\title{
New Infectious Etiologies for Posterior Uveitis
}

\author{
Moncef Khairallah Rim Kahloun Salim Ben Yahia Bechir Jelliti \\ Riadh Messaoud \\ Department of Ophthalmology, Fattouma Bourguiba University Hospital, Faculty of Medicine, University of \\ Monastir, Monastir, Tunisia
}

\section{Key Words}

Arthropod borne-diseases • Posterior uveitis · Retinitis •

Chorioretinitis • Vasculitis

\begin{abstract}
Emergent and resurgent arthropod vector-borne diseases are major causes of systemic morbidity and death and expanding worldwide. Among them, viral and bacterial agents including West Nile virus, Dengue fever, Chikungunya, Rift Valley fever, and rickettsioses have been recently associated with an array of ocular manifestations. These include anterior uveitis, retinitis, chorioretinitis, retinal vasculitis and optic nerve involvement. Proper clinical diagnosis of any of these infectious diseases is based on epidemiological data, history, systemic symptoms and signs, and the pattern of ocular involvement. The diagnosis is usually confirmed by the detection of a specific antibody in serum. Ocular involvement associated with emergent infections usually has a selflimited course, but it can result in persistent visual impairment. There is currently no proven specific treatment for arboviral diseases, and therapy is mostly supportive. Vaccination for humans against these viruses is still in the research phase. Doxycycline is the treatment of choice for rickettsial diseases. Prevention, including public measures to reduce the number of mosquitoes and personal protection,
\end{abstract}

remains the mainstay for arthropod vector disease control. Influenza A (H1N1) virus was responsible for a pandemic human influenza in 2009, and was recently associated with various posterior segment changes.

Copyright $\odot 2012$ S. Karger AG, Basel

\section{Introduction}

Arthropod vector-borne diseases are among the most important emergent and resurgent infections. They include a wide variety of viral, bacterial and parasitic diseases that are transmitted to humans by the bite of an arthropod such as a mosquito or tick. Most of them are prevalent in tropical and subtropical areas, but they tend to spread into new regions mainly due to climate changes and globalization. Systemic disease may range from mild febrile illness to severe, potentially lethal systemic involvement. Specific viral and bacterial arthropod vectorborne infections have been recently associated with posterior uveitis and other ocular manifestations [1-3]. They include viral diseases, namely West Nile virus (WNV) infection, Rift Valley fever (RVF), Dengue fever (DF), Chikungunya, and rickettsioses. There is currently no proven specific treatment for arboviral diseases, and therapy is mostly supportive. Prevention, including pub-

\section{KARGER}

Fax +4161306 1234 E-Mail karger@karger.ch www.karger.com
(C) 2012 S. Karger AG, Basel

0030-3747/13/0492-0066\$38.00/0

Accessible online at:

www.karger.com/ore
Moncef Khairallah, MD

Department of Ophthalmology

Fattouma Bourguiba University Hospital

TN-5019 Monastir (Tunisia)

E-Mail moncef.khairallah@rns.tn 
lic measures to reduce the number of mosquitoes and personal protection, remains the mainstay for arthropod vector disease control. In this article, we review the epidemiological, systemic, and ocular features of these selected arthropod vector-borne diseases relevant to the ophthalmologist. Influenza A (H1N1) virus-associated ocular disease will also be briefly discussed.

\section{WNV Infection}

WNV infection is a zoonotic disease caused by a single-stranded RNA flavivirus and transmitted to human by a mosquito vector (type Culex) with wild birds serving as its reservoir [1-3]. The virus is widely distributed in Africa, Europe, Australia and Asia, and since 1999 it has spread rapidly throughout the Western hemisphere, including the United States, Canada, Mexico and the Caribbean and into parts of Central and South America [13]. Most human infections are subclinical (80\%) or manifest as febrile illness (20\%) [1-3]. Severe neurological disease was reported to occur in less than $1 \%$ of patients and was frequently associated with advanced age and diabetes [3]. The diagnosis is confirmed by the detection of IgM antibody in serum or cerebrospinal fluid and/or by PCR [4].

Typical bilateral or rarely unilateral multifocal chorioretinitis is the most common ocular manifestation of WNV infection, occurring in almost $80 \%$ of patients with acute WNV infection associated with neurological illness $[5,6]$. Most patients have no ocular symptoms or present with mildly reduced vision or floaters. Active chorioretinal lesions present as circular, deep, yellowish lesions on ophthalmoscopy (fig. 1), with early hypofluorescence and late staining on fluorescein angiography (FA) [5]. Inactive chorioretinal lesions appear as round, atrophic lesions with or without central pigmentation (fig. 2a), and they usually exhibit a typical 'target-like appearance' on FA (fig. 2b) with central hypofluorescence and peripheral hyperfluorescence [5]. Chorioretinal lesions vary in number and size, involving the midperiphery, with or without associated posterior pole involvement [5]. They are typically oriented radially in the nasal and peripheral fundus or arranged in a curvilinear pattern in the temporal posterior fundus [5]. The linear pattern of chorioretinitis appears to be related to the course of retinal nerve fibers [7]. Indocyanine green angiography shows well-delineated hypofluorescent choroidal spots with more lesions than those appreciated clinically or on FA [8]. Most patients with chorioretinitis are above

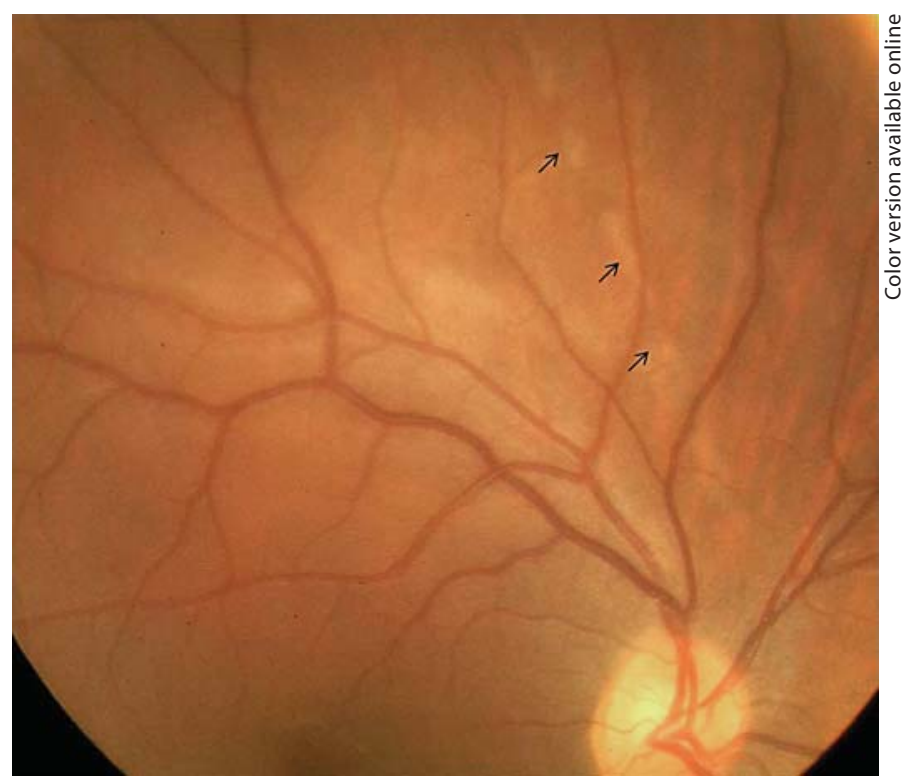

Fig. 1. Color fundus photograph of the right eye of a young patient with WNV infection shows superotemporal, linear clustering of deep, creamy, active chorioretinal lesions (arrows).

50 years of age and have diabetes mellitus, with a substantial proportion of them exhibiting associated diabetic retinopathy [9]. Although multifocal chorioretinitis is the most common ocular manifestation of WNV infection, other manifestations have been described, including retinal hemorrhages, focal or diffuse retinal vascular sheathing, vascular leakage, occlusive vasculitis, zones of atrophy and mottling of retinal pigment epithelium (RPE), macular edema, and optic neuritis $[1-3,5,6]$. Ocular disease associated with WNV infection usually has a selflimited course, and visual acuity returns to baseline in most patients [5]. However, persistent visual loss may occur due to foveal chorioretinal scar, choroidal neovascularization, vitreous hemorrhage, tractional retinal detachment, severe ischemic maculopathy, optic atrophy, and retrogeniculate damage $[1-3,5,6,10,11]$. Recently, one case of reactivation of WNV infection-related chorioretinitis has been reported [12].

There is, at present, no proven treatment for WNV infection. In cases of severe systemic disease, intensive supportive therapy is indicated $[1-3,13,14]$. Antiviral agents such as ribavirin and interferon were found to be active only in vitro [3]. Several clinical trials of interferon- $\alpha-2 b$, interferon beta, and high-titer intravenous immunoglobulin will allow new and more effective therapeutic approaches to emerge in future $[13,14]$. 


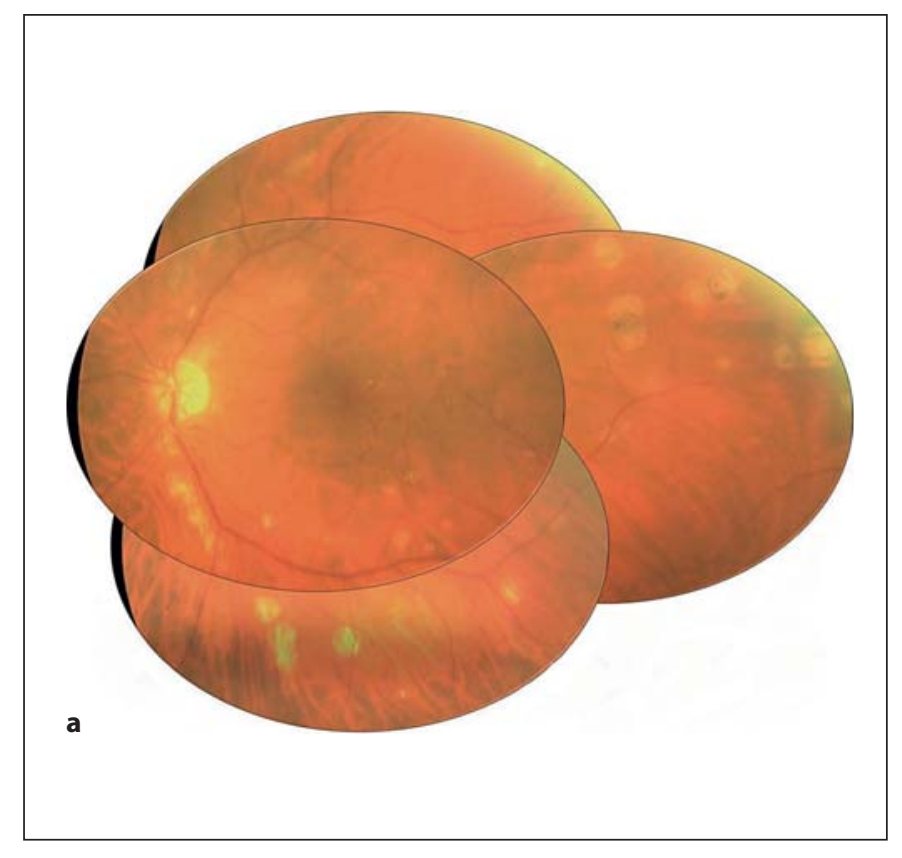

Fig. 2. Color fundus photograph (a) and fluorescein angiogram (b) of the left eye of a diabetic patient with WNV infection show inactive multifocal chorioretinitis with typical linear clustering and 'target-like appearance' of chorioretinal lesions.

Specific ophthalmic treatments that may be required include topical steroids for anterior uveitis, peripheral retinal photocoagulation for neovascularization owing to occlusive vasculitis, pars plana vitrectomy for nonclearing vitreous hemorrhage or tractional retinal detachment, and intravitreal injection of antivascular endothelial growth factor agent for choroidal neovascularization or macular edema $[11,15]$.

\section{Dengue Fever}

DF is caused by the Dengue virus, a flavivirus transmitted by the Aedes aegypti mosquito. The disease is considered to be one of the most important Arthropod vector-borne diseases in the tropical and subtropical regions [1-3]. In addition to fever, DF may cause headache, myalgia, thrombocytopenia and Dengue shock syndrome [13]. The diagnosis of DF is based on the typical clinical presentation and a positive Dengue IgM serology [1-3]. Ocular involvement, usually bilateral, is common in patients with DF [1-3]. The patients may complain of a sudden decrease in vision, a central scotoma, or floaters. A subconjunctival hemorrhage, petechial in type and asso-

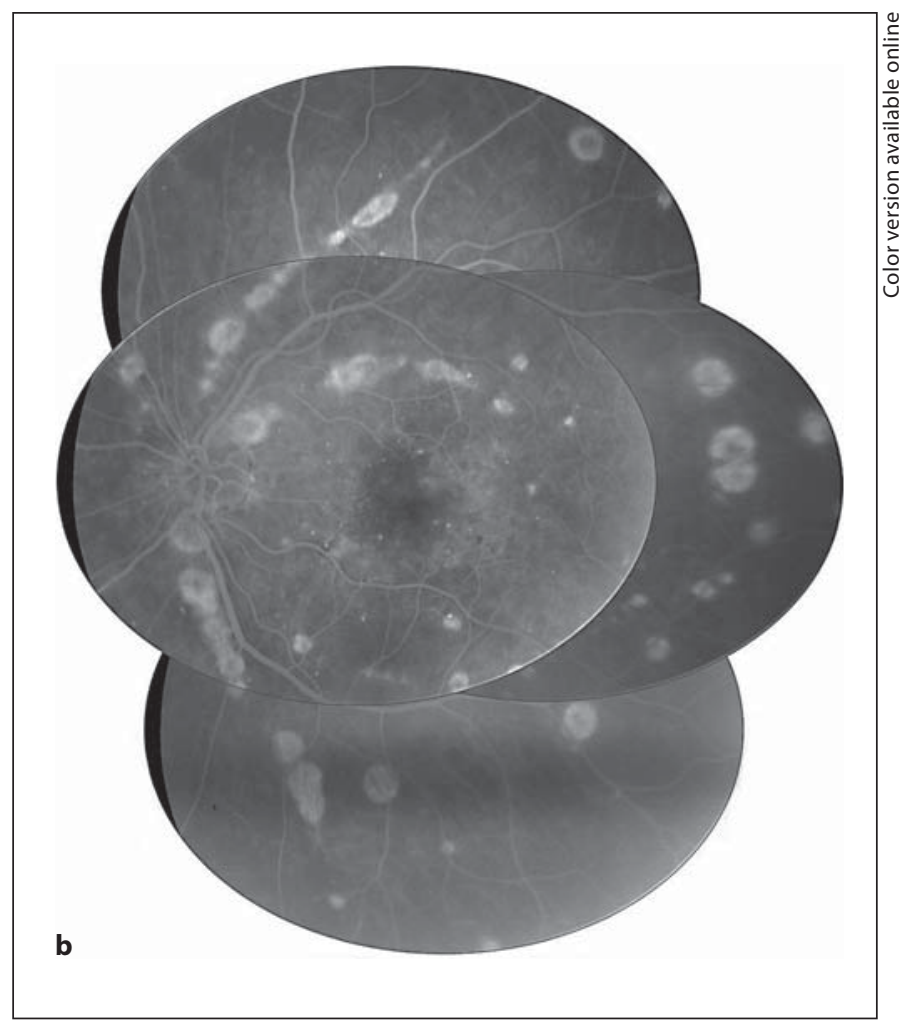

ciated with a platelet count of less than $50,000 / \mu$ is common [3]. Numerous posterior segment changes can occur in association with DF, including retinal hemorrhages, retinal vascular sheathing, yellow subretinal dots, RPE mottling, foveolitis (seen clinically as a round yellowish lesion at the fovea; fig. 3a), choroidal changes, optic disc swelling, optic neuritis, and neuroretinitis [1-3, 16-23]. There may also be cells in the anterior chamber or vitreous humor. The most common fluorescein angiographic findings include retinal vascular leakage and occlusion. Indocyanine green angiography shows hypofluorescent spots corresponding to the subretinal lesions seen clinically and additional spots in areas without clinically evident dots [17]. Large choroidal vasculopathy with hyperfluorescence and leakage is also common. Optical coherence tomography (OCT) is useful in detecting and monitoring the progress of foveolitis [24], showing a focal outer neurosensory RPE thickening corresponding to the round foveal yellowish lesion seen clinically (fig. 3b). OCT is also useful in the detection and evaluation of serous retinal detachment (SRD) and macular edema. Although the visual prognosis is good in most patients, Dengue-associated maculopathy and neuropathy may result in permanent visual impairment [24]. Ocular in- 


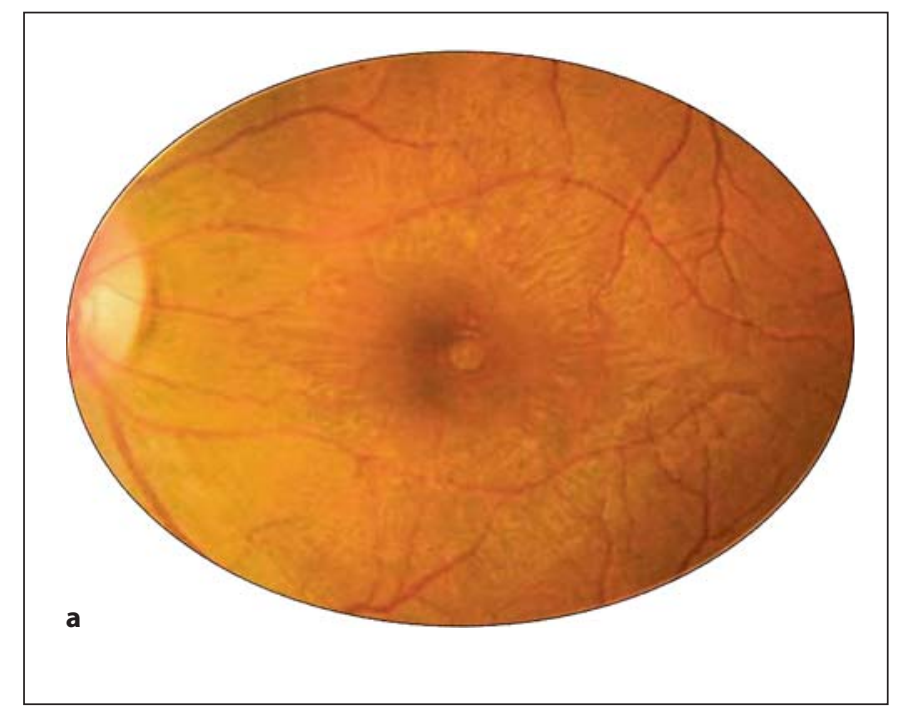

volvement in DF may be self-limiting [1-3] and there have been no prospective randomized trials on therapy to date. Treatment with topical, periocular, oral, intravenous steroids and immunoglobulins has been attempted with variable success $[16,18]$.

\section{Chikungunya Virus Infection}

Chikungunya virus is a single-stranded RNA virus of the genus Alphavirus in the family Togaviridae transmitted to humans by the bite of infected Aedes mosquitoes, primarily $A$. aegypti [1-3]. The virus has been associated with many epidemics in tropical regions of Africa, India, Southeast Asia and South America [1-3]. Chikungunya fever may manifest as an acute fever with headache, fatigue, myalgia, diffuse maculopapular rash, bleeding from the nose or gums, peripheral edema, joint pain neurological signs, acute hepatic failure, multiorgan failure, mother-to-child transmission, and vision-threatening ocular complications [1-3].

Ocular symptoms usually occur after a latent period of a month to a year; however, a few concurrent presentations have also been reported. Ocular involvement in Chikungunya is either unilateral or bilateral, affecting both genders in all age groups, with anterior uveitis and retinitis as the most common ocular manifestations [1-3, 25].

Chikungunya retinitis or retinochoroiditis is usually accompanied by mild vitritis and presents in the form of areas of retinal whitening in the posterior pole with sur-

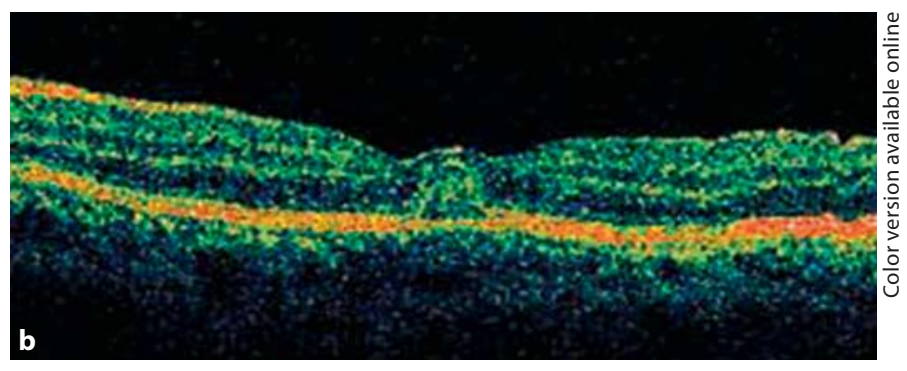

Fig. 3. a Color fundus photograph of the left eye of a patient with DF shows a subretinal round, yellowish lesion at the fovea. $\mathbf{b}$ OCT shows a corresponding focal outer neurosensory RPE thickening (courtesy of Soon-Phaik Chee).

rounding retinal and macular edema (fig. 4). Associated occlusive vasculitis, accurately detected by FA, is also common [1-3, 25-27]. Other posterior segment involvements include optic neuritis, neuroretinitis, central retinal artery occlusion, and exudative retinal detachment [25-29]. Although ocular manifestations have typically a benign clinical course, optic neuritis may result in permanent visual loss. Some investigators treat confluent retinitis with intravenous/oral acyclovir and oral prednisolone, although there is no evidence in the literature to support the efficacy of acyclovir or other antiviral agents against Chikungunya [1-3].

\section{Rift Valley Fever}

RVF is an arthropod-borne viral disease caused by Bunyaviridae. It is transmitted to humans through a bite by infected mosquitoes or through direct contact with infected animals. Several outbreaks have been reported in sub-Saharan and North Africa, and more recently in the Arabian Peninsula [1-3]. The main symptoms are fever with biphasic temperature curve, headache, arthralgia, myalgia, and gastrointestinal disturbances [1-3]. Other clinical presentations include a hemorrhagic fever with liver involvement, thrombocytopenia, icterus and bleeding tendencies, and a neurological involvement with encephalitis after a febrile episode with confusion and coma [1-3]. Ocular involvement has been reported to occur in $1-20 \%$ of RVF infections $[1-3,30]$. The mean interval between the onset of RVF and visual symptoms 


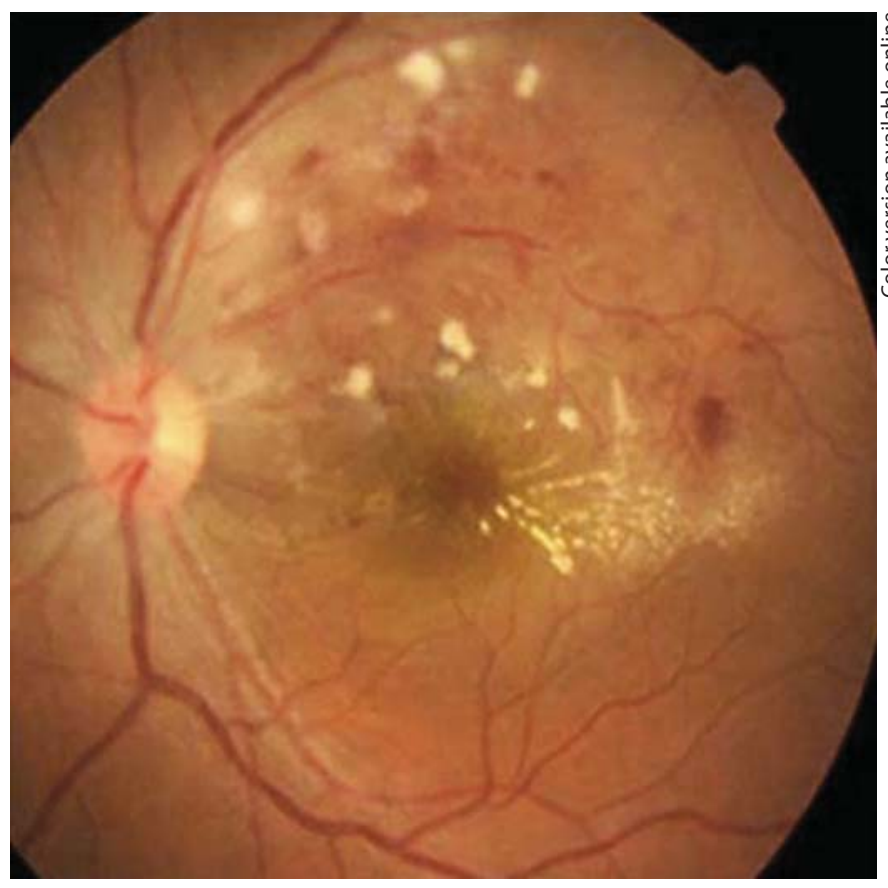

Fig. 4. Fundus photograph of the left eye of a patient with Chikungunya shows hyperemic optic disc, numerous white retinal lesions, superficial hemorrhages, and an incomplete macular star (courtesy of Padmamalini Mahendradas).

ranges from 4 to 15 days. Macular or paramacular retinitis is the most common finding (fig. 5). Foci of retinitis show early hypofluorescence with late staining of retinal lesions and retinal vascular leakage on FA. Other posterior segment lesions include retinal hemorrhages, vitritis, optic disc edema, and retinal vasculitis [1-3, 30]. Symptoms resolve spontaneously within 2-3 weeks from the onset of systemic symptoms, but permanent visual loss is common, resulting from macular and paramacular scarring, vascular occlusion, or optic atrophy $[1-3,30]$.

Treatment is entirely supportive. For mild to moderate cases of RVF, simple analgesia and fluids can be administered [1-3]. For patients who develop severe disease, aggressive critical care including assisted ventilation and blood product transfusion is essential [1-3].

\section{Rickettsioses}

Rickettsioses are worldwide-distributed zoonoses due to obligate intracellular small Gram-negative bacteria. Most of them are transmitted to humans by the bite of contaminated arthropods such as ticks [1-3]. Rickettsial

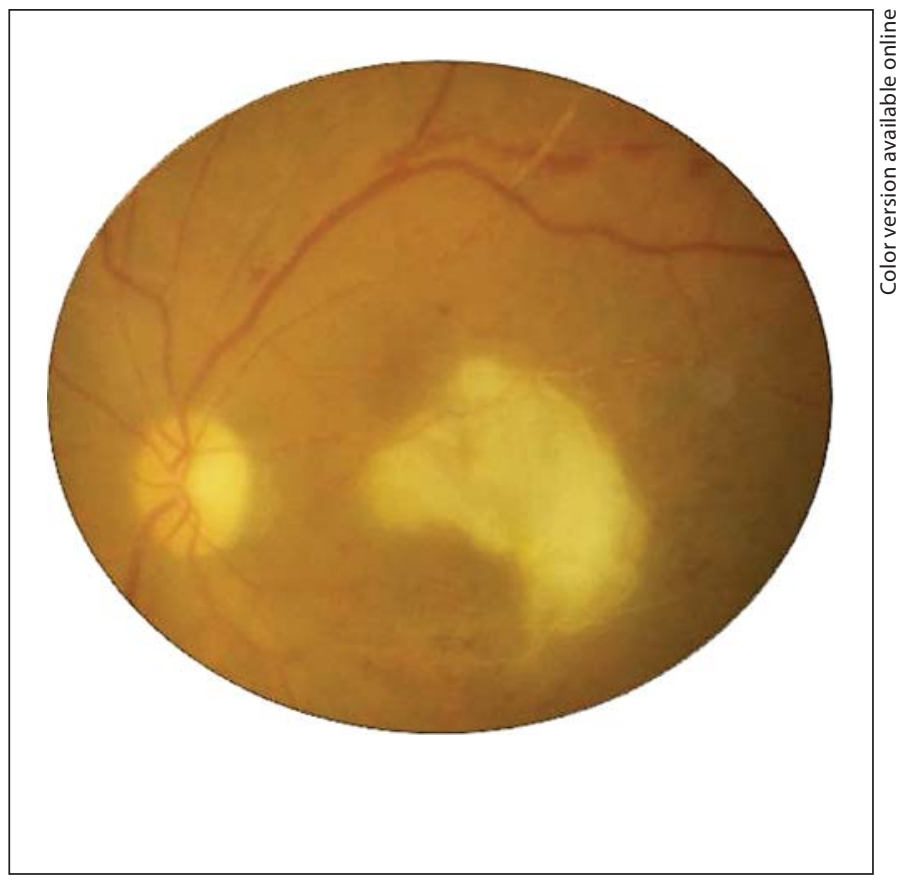

Fig. 5. Fundus photograph of the left eye of a patient with RVF shows macular retinitis with associated retinal vascular sheathing and retinal hemorrhages (courtesy of Emad Abboud).

agents are classified into three major categories: the spotted fever group, the typhus group, and the scrub typhus group [1-3]. A rickettsial disease should be suspected, during spring or summer, in the presence of the triad of high fever, headache and general malaise, and skin rash in a patient living in or traveling back from a region endemic for rickettsioses [1-3]. Ocular involvement is common in patients with rickettsioses, but since it is frequently asymptomatic and self-limited, it may be easily overlooked [1-3, 31-33]. Inner retinitis with or without associated mild or moderate vitritis is the most common clinical finding [1-3, 31-33]. It presents in the form of white retinal lesions typically adjacent to retinal vessels (fig. 6a) and variable in number, size and location. FA shows early hypofluorescence and late staining of large retinal lesions (fig. 6b) and slight hypofluorescence or isofluorescence of small retinal lesions [31, 32]. SRD, accurately detected by OCT, frequently accompanies large foci of rickettsial retinitis. Retinal vascular lesions in patients with rickettsial disease may include focal or diffuse vascular sheathing, vascular leakage, retinal hemorrhages, and retinal vascular occlusions, including branch retinal artery occlusion and branch retinal vein occlusion or 

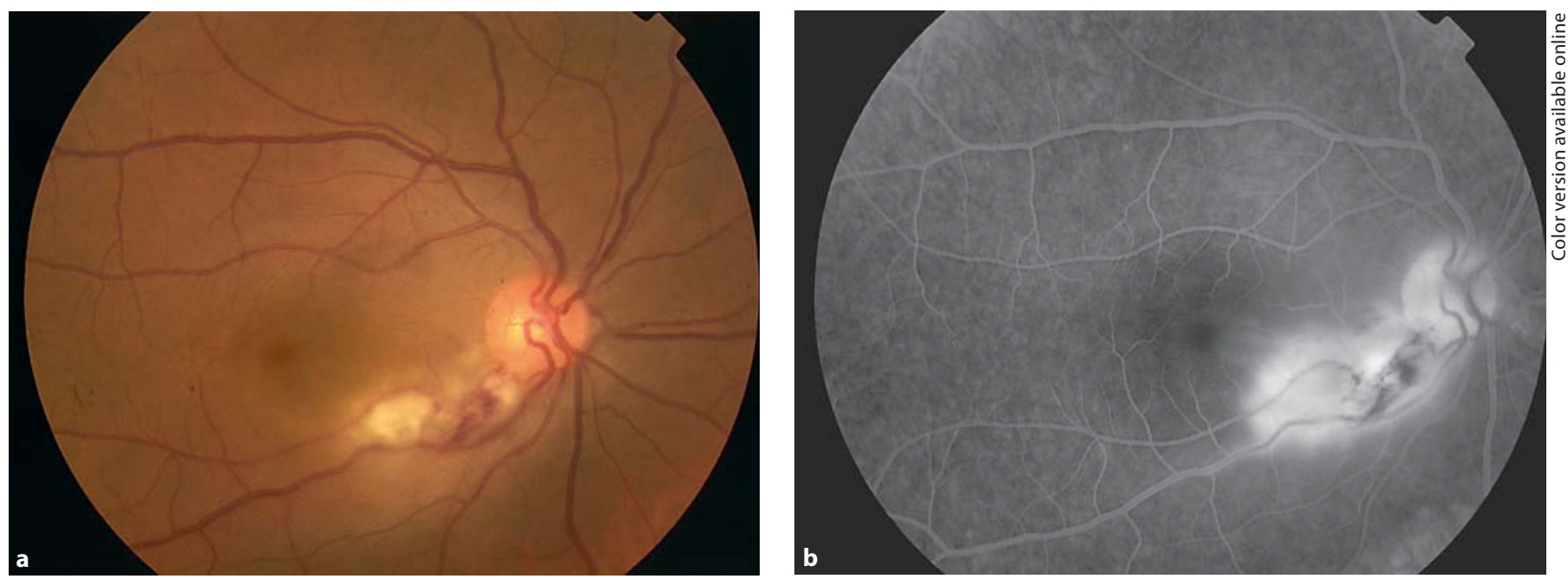

Fig. 6. a Color fundus photograph of the right eye of a patient with rickettsial disease shows white retinal lesions adjacent to the inferior vascular arcade and close to the optic disc associated with retinal hemorrhages. b Late-phase fluorescein angiogram shows staining of the retinal lesions with retinal vascular leakage and optic disc hyperfluorescence.

subocclusion, leading to retinal neovascularization and vitreous hemorrhage [1-3,31-34]. A subclinical choroidal involvement in the form of multiple dark dots on FA was observed in more than $15 \%$ of patients with Mediterranean spotted fever [31]. Indocyanine green angiography shows small hypofluorescent spots in the intermediate and late phases, areas of hyperfluorescence, choroidal vascular filling defect, and choroidal vascular staining [32]. Other chorioretinal changes include cystoid macular edema and endophthalmitis [1-3, 31-34]. Optic disc involvement may include optic disc edema, optic disc staining, optic neuritis, neuroretinitis, and ischemic optic neuropathy $[1-3,35]$. Ophthalmic involvement in rickettsioses often has a self-limited course. Foci of retinitis usually disappear without causing scarring in 3-10 weeks. Persistent decreased vision may occur in cases of retinal changes secondary to macular edema or SRD, retinal artery or vein occlusion, foveal chorioretinal scar, or optic neuropathy [1-3, 31-34]. Doxycycline is the drug of choice for the treatment of rickettsial diseases $[1-3,31$, 32]. Systemic steroids may be required for severe ophthalmic involvement [1-3, 31, 32].

\section{H1N1 Uveitis}

Influenza $\mathrm{A}(\mathrm{H} 1 \mathrm{~N} 1)$ virus was the most common cause of human influenza in 2009. Patients infected with H1N1 may present with flu symptoms such as fever, cough and

body aches [36, 37]. Ocular involvement has been recently associated with $\mathrm{H} 1 \mathrm{~N} 1 \mathrm{infection}$, as well as vaccination. It includes retinitis, choroiditis, submacular hemorrhages, macular edema, cotton wool spots, frosted branch angiitis, neuroretinitis, SRD, optic disc edema, and uveal effusion [36-41]. Ocular involvement is favorable in the majority of reported cases [36-41]. Frosted branch angiitis, macular edema, and uveal effusion may be treated with oral prednisone $[38,40]$.

\section{Disclosure Statement}

The authors have no financial interests to disclose.

References

Ophthalmic Res 2013;49:66-72
Khairallah M, Jelliti B, Jenzeri S: Emergent infectious uveitis. Middle East Afr J Ophthalmol 2009;16:225-238.

-2 Khairallah M, Chee SP, Rathinam SR, Attia S, Nadella V: Novel infectious agents causing uveitis. Int Ophthalmol 2010;30:465-483.

-3 Khairallah M, Yahia SB, Attia S: Arthropod vector-borne uveitis in the developing world. Int Ophthalmol Clin 2010;50:125-144.

-4 Shukla J, Saxena D, Rathinam S, Lalitha P, Joseph CR, Sharma S, Soni M, Rao PV, Parida M: Molecular detection and characterization of West Nile virus associated with multifocal retinitis in patients from southern India. Int J Infect Dis 2012;16:e53-e59. 
5 Khairallah M, Ben Yahia S, Ladjimi A, Zeghidi H, Ben Romdhane F, Besbes L, Zaouali S, Messaoud R: Chorioretinal involvement in patients with West Nile virus infection. Ophthalmology 2004;111:20652070.

6 Chan CK, Limstrom SA, Tarasewicz DG, Lin SG: Ocular features of West Nile virus infection in North America: a study of 14 eyes. Ophthalmology 2006;113:1539-1546.

$\checkmark 7$ Khairallah M, Ben Yahia S, Attia S, Zaouali S, Ladjimi A, Messaoud R: Linear pattern of West Nile virus-associated chorioretinitis is related to retinal nerve fibres organization. Eye (Lond) 2007;21:952-955.

$\checkmark 8$ Khairallah M, Ben Yahia S, Attia S, Zaouali S, Jelliti B, Jenzri S, Ladjimi A, Messaoud R: Indocyanine green angiographic features in multifocal chorioretinitis associated with West Nile virus infection. Retina 2006;26: 358-359.

$>9$ Khairallah M, Yahia SB, Letaief M, Attia S, Kahloun R, Jelliti B, Zaouali S, Messaoud R: A prospective evaluation of factors associated with chorioretinitis in patients with West Nile virus infection. Ocul Immunol Inflamm 2007; 15:435-439.

10 Khairallah M, Ben Yahia S, Attia S, Jelliti B, Zaouali S, Ladjimi A: Severe ischemic maculopathy in a patient with West Nile virus infection. Ophthalmic Surg Lasers Imaging 2006;37:240-242.

-11 Seth RK, Stoessel KM, Adelman RA: Choroidal neovascularization associated with West Nile virus chorioretinitis. Semin Ophthalmol 2007;22:81-84.

12 Beardsley R, McCannel C: Reactivation West Nile virus infection-related chorioretinitis. Semin Ophthalmol 2012;27:43-45.

-13 Ben-Nathan D, Gershoni-Yahalom O, Samina I, Khinich Y, Nur I, Laub O, Gottreich A, Simanov M, Porgador A, Rager-Zisman B, Orr N: Using high titer West Nile intravenous immunoglobulin from selected Israeli donors for treatment of West Nile virus infection. BMC Infect Dis 2009;9:18.

-14 Lazear HM, Pinto AK, Vogt MR, Gale M Jr, Diamond MS: Beta interferon controls West Nile virus infection and pathogenesis in mice. J Virol 2011;85:7186-7194.

- 15 Afshar AR, Hariprasad SM, Jampol LM, Sheth VS: Use of intravitreous bevacizumab to treat macular edema in West Nile virus chorioretinitis. Arch Ophthalmol 2012;130: 396-398.
16 Lim WK, Mathur R, Koh A, Yeoh R, Chee SP: Ocular manifestations of dengue fever. Ophthalmology 2004;111:2057-2064.

17 Loh BK, Bacsal K, Chee SP, Cheng BC, Wong D: Foveolitis associated with dengue fever: a case series. Ophthalmologica 2008;222:317320.

18 Bacsal KE, Chee SP, Cheng CL, Flores JV: Dengue-associated maculopathy. Arch Ophthalmol 2007;125:501-510.

19 Su DH, Bacsal K, Chee SP, Flores JV, Lim WK, Cheng BC, Jap AH, Dengue Maculopathy Study Group: Prevalence of dengue maculopathy in patients hospitalized for dengue fever. Ophthalmology 2007;114:1743-1747.

20 Chee E, Sims JL, Jap A, Tan BH, Oh H, Chee SP: Comparison of prevalence of dengue maculopathy during two epidemics with differing predominant serotypes. Am J Ophthalmol 2009;148:910-913.

-21 Tabbara K: Dengue retinochoroiditis. Ann Saudi Med 2012;32:530-533.

22 Beral L, Merle H, David T: Ocular complications of dengue fever. Ophthalmology 2008; 115:1100-1101.

23 Aragão RE, Barreira IM, Lima LN, Rabelo LP, Pereira FB: Bilateral optic neuritis after dengue viral infection: case report (in Portugese). Arq Bras Oftalmol 2010;73:175-178.

$\checkmark 24$ Teoh SC, Chee CK, Laude A, Goh KY, Barkham T, Ang BS, Eye Institute DengueRelated Ophthalmic Complications Workgroup: Optical coherence tomography patterns as predictors of visual outcome in dengue-related maculopathy. Retina 2010;30: 390-398.

${ }_{25}$ Lalitha P, Rathinam S, Banushree K, Maheshkumar S, Vijayakumar R, Sathe P: Ocular involvement associated with an epidemic outbreak of chikungunya virus infection. Am J Ophthalmol 2007;144:552-556.

26 Chanana B, Azad RV, Nair S: Bilateral macular choroiditis following Chikungunya virus infection. Eye (Lond) 2007;21:1020-1021.

27 Mahendradas P, Ranganna SK, Shetty R, Balu R, Narayana KM, Babu RB, Shetty BK: Ocular manifestations associated with chikungunya. Ophthalmology 2008;115:287291.

-28 Murthy KR, Venkataraman N, Satish V, Babu K: Bilateral retinitis following chikungunya fever. Indian J Ophthalmol 2008;56: 329-331.

-29 Mahesh G, Giridhar A, Shedbele A, Kumar R, Saikumar SJ: A case of bilateral presumed chikungunya neuroretinitis. Indian J Ophthalmol 2009;57:148-150.
30 Al-Hazmi A, Al-Rajhi AA, Abboud EB, Ayoola EA, Al-Hazmi M, Saadi R, Ahmed N: Ocular complications of Rift Valley fever outbreak in Saudi Arabia. Ophthalmology 2005;112:313-318.

31 Khairallah M, Ladjimi A, Chakroun M, Messaoud R, Ben Yahia S, Zaouali S, Ben Romdhane F, Bouzouaia N: Posterior segment manifestations of Rickettsia conorii infection. Ophthalmology 2004;111:529-534.

-32 Khairallah M, Ben Yahia S, Toumi A, Jelliti B, Loussaief C, Romdhane FB, Messaoud R, Chakroun M: Ocular manifestations associated with murine typhus. Br J Ophthalmol 2009;93:938-942.

33 Khairallah M, Yahia SB, Jelliti B, Ben Romdhane F, Loussaief C, Attia S, Toumi A, Messaoud R, Chakroun M: Diagnostic value of ocular examination in Mediterranean spotted fever. Clin Microbiol Infect 2009; 15(suppl 2):273-274.

-34 Agahan AL, Torres J, Fuentes-Páez G, Martínez-Osorio $\mathrm{H}$, Orduña A, Calonge M: Intraocular inflammation as the main manifestation of Rickettsia conorii infection. Clin Ophthalmol 2011;5:1401-1407.

35 Khairallah M, Zaouali S, Ben Yahia S, Ladjimi A, Messaoud R, Jenzeri S, Attia S: Anterior ischemic optic neuropathy associated with Rickettsia conorii infection. J Neuroophthalmol 2005;25:212-214.

36 Faridi OS, Ranchod TM, Ho LY, Ruby AJ: Pandemic 2009 influenza A H1N1 retinopathy. Can J Ophthalmol 2010;45:286-287.

37 Rifkin L, Schaal S: H1N1-associated acute retinitis. Ocul Immunol Inflamm 2012;20: $230-232$.

38 Jo T, Mizota A, Hatano N, Tanaka M: Frosted branch angiitis-like fundus following presumed influenza virus type A infection. Jpn J Ophthalmol 2006;50:563-564.

39 Tao Y, Chang LB, Zhao M, Li XX: Two cases of exudative retinal detachment and uveitis following $\mathrm{H} 1 \mathrm{~N} 1$ influenza vaccination. Chin Med J (Engl) 2011;124:3838-3840.

40 Roesel M, Heinz C, Heiligenhaus A: H1N1 and uveal effusion syndrome. Ophthalmology 2010;117:1467-1467.e1.

41 Mansour DE, El-Shazly AA, Elawamry AI, Ismail AT: Comparison of ocular findings in patients with H1N1 influenza infection versus patients receiving influenza vaccine during a pandemic. Ophthalmic Res 2012;48: 134-138. 